DOI: $10.47456 / k r k r . v 1 i 9.28688$

\title{
A Universidade como espaço complementar ao Ensino de Botânica no Ensino Médio
}

The University as a complementary space to the Teaching of Botany in High School

\author{
Fabiane Fonseca Ribeiro \\ Elisa Mitsuko Aoyama \\ Marcos da Cunha Teixeira \\ Luis Fernando Tavares de Menezes
}

Resumo: O ensino de botânica, muitas vezes, é abordado de forma descontextualizada com a realidade dos alunos, pois as aulas são excessivamente teóricas e descritivas, interferindo no processo de aprendizagem e estímulo desses. Assim, faz-se necessário utilizar estratégias capazes de dinamizar essas dificuldades relacionados com o ensino dos vegetais. Desse modo, esse relato tem como objetivo descrever a experiência vivenciada por estudantes de graduação no ensino de botânica, utilizando práticas e recursos diversificados para facilitar o processo de ensino-aprendizagem sobre as características adaptativas e morfoanatômicas das plantas de diferentes vegetações. Foram realizadas uma aula expositiva dialogada e uma prática, na qual ocorreram em sequência no Laboratório de Botânica Estrutural, situado no Centro Universitário Norte do Espírito Santo, localizado em São Mateus, Espírito Santo. O público alvo foram alunos da $2^{a}$ série do Ensino Médio. Os monitores ministraram alguns conhecimentos sobre célula vegetal; técnicas de utilização do microscópio óptico; técnicas usuais de anatomia vegetal, como planos de corte e montagem de lâminas temporárias e adaptações morfoanatômicas das plantas ao ambiente. Após essas explanações, ocorreu a aula prática com materiais vegetais que evidenciavam essas adaptações. Por fim, foi aplicado um jogo online, contribuindo com o processo de ensino-aprendizagem. A partir dos resultados obtidos, pôde ser observado que o método pedagógico foi eficaz e que contribuiu com o aprendizado sobre os assuntos botânicos abordados. Sendo assim, essa experiência foi importante na formação profissional, contribuindo para o desenvolvimento da autonomia, interação e desenvolvimento de habilidades dos estudantes de graduação para com os de Ensino Médio.

Palavras-chave: relato de experiência, projeto de extensão, laboratório, recursos tecnológicos, formação profissional.

Abstract: The teaching of botany is often approached in a way that is decontextualized with the reality of the students, because the classes are excessively theoretical and descriptive, interfering in the process of learning and stimulating them. Thus, it is necessary to use strategies capable of boosting these difficulties related to the teaching of vegetables. Thus, this report aims to describe the experience experienced by undergraduate students in botany teaching, using diversified practices and resources to facilitate the teaching-learning process on the adaptive and morphoanatomical characteristics of plants of different vegetations. A dialogued expository class and a practice were held, in which they took place in sequence in the Laboratory of Structural Botany, located in the Centro Universitário Norte do Espírito Santo, in São Mateus, Espírito Santo. Target audiences were students of the $2^{\mathrm{a}}$ series of high school. The monitors provided some knowledge about the plant cell; techniques for the use of the optical microscope; usual techniques of plant anatomy, such as 
cutting planes and assembling temporary slides and morphoanatomical adaptations of plants to the environment. After these explanations, the practical class occurred with plant materials that evidenced these adaptations. Finally, an online game was applied, contributing to the teaching-learning process. From the results obtained, it could be observed that the pedagogical method was effective and that it contributed to the learning about the botanical subjects addressed. Thus, this experience was important in professional training, contributing to the development of autonomy, interaction and skills development of undergraduate students towards high school students.

Keywords: experience report, extension project, laboratory, technological resources, professional training.

\section{Introdução}

A Botânica, é o ramo da Biologia que estuda os vegetais e está presente no currículo escolar do ensino básico, embora seja considerado, por alguns docentes, um tema subestimado (KATON et al., 2013). Assim, torna-se importante que o professor utilize métodos pedagógicos capazes de diminuir a valorização da memorização de nomes e conceitos botânicos (MELO et al., 2012), como aulas mais expositivas, dialogadas e práticas.

Anastasiou e Alves (2004, p. 15) apontam que uma aula expositiva dialogada é:

Uma exposição do conteúdo, com a participação ativa dos estudantes, cujo conhecimento prévio deve ser considerado e pode ser tomado como ponto de partida. O professor leva os estudantes a questionarem, interpretarem e discutirem o objeto de estudo, a partir do reconhecimento e do confronto com a realidade. Deve favorecer análise crítica, resultando na produção de novos conhecimentos. Propõe a superação da passividade e imobilidade intelectual dos estudantes.

Vale destacar outro método pedagógico existente: a aula prática, que propicia aos alunos a experiência de vivenciar a ciência. Katon et al. (2013, p.180) relatam a importância de aulas práticas para o conhecimento de Botânica:

As aulas práticas são muito importantes também para a aprendizagem do aluno nas aulas de Botânica, pois são uma oportunidade de relacionar os conteúdos teóricos com o seu dia-a-dia e perceber que a matéria aprendida nos livros não está distante do seu cotidiano. [...] Dar ênfase em atividades que explicitem o estudante como integrante da natureza, interagindo com ela, faz com que o aluno perceba sentindo, emocionando-se ao relacionar-se com o meio. A utilização desse tipo de atividade permite o contato com outras formas de 
conhecimentos não conteudistas, como por exemplo, como proceder em um ambiente de laboratório ou como agir ao lidar com competição, ao escolher e efetivar uma atividade, o professor propõe aos alunos a realização de diversas operações mentais num processo de crescente complexidade do pensamento.

Nesse contexto, Salatino e Buckeridge (2016) relatam que a utilização de aulas práticas sobre as plantas propicia a participação ativa dos alunos, estimulando-os na construção do conhecimento sobre a Botânica. Além disso, funcionam como um complemento das aulas teóricas, auxiliando na construção e fixação do conhecimento. Corroborando essa ideia, Bombonato (2011) afirma que é essencial utilizar atividades práticas, como forma de compreender conceitos e incentivar o aluno a participar do seu processo de aprendizagem.

Sabe-se que as atividades práticas podem ocorrer na sala de aula, em espaços não formais de ensino e principalmente em laboratórios. Segundo Hofstein e Lunetta (2003) houve um crescimento na qualidade de ferramentas utilizadas nos laboratórios, implicando, assim, no ensino, na aprendizagem e nas pesquisas. As principais funções para aulas de laboratório presentes na literatura são: "despertar e manter o interesse dos alunos; envolver os estudantes em investigações científicas; desenvolver a capacidade de resolver problemas; compreender conceitos básicos e desenvolver habilidades" (KRASILCHIK, 2016 apud HOFSTEIN, 1982).

Convém ressaltar que em muitas escolas públicas brasileiras existem limitações relacionadas aos espaços físicos, ausência de equipamentos, laboratórios, materiais adequados, entre outros fatores, dificultando muitas vezes o trabalho do professor, por conseguinte, o processo educativo. Assim, faz-se necessário realizar visitas em espaços não formais como estratégias de ensino. Bortoletto (2013) afirma que os espaços educativos não formais são capazes de oferecer condições favoráveis ao desenvolvimento de atividades interativas, de caráter lúdico e de divulgação científica. Além de proporcionar inúmeras possibilidades didáticas como recursos de aprendizagem, ultrapassando o espaço de sala de aula, contribuindo com a compreensão e assimilação dos conteúdos ministrados (BEZERRA et al., 2013). 
Sabe-se que o Ensino de Botânica, muitas vezes, é abordado de forma descontextualizada com a realidade dos alunos, pois as aulas são excessivamente teóricas e descritivas, interferindo no processo de aprendizagem e estímulo desses. Assim, faz-se necessário utilizar estratégias capazes de dinamizar essas dificuldades relacionados com o ensino dos vegetais.

Desse modo, esse relato tem como objetivo descrever a experiência vivenciada por estudantes de graduação no ensino de botânica, utilizando práticas e recursos diversificados para facilitar o processo de ensinoaprendizagem sobre as características adaptativas e morfoanatômicas das plantas de diferentes vegetações.

\section{Metodologia}

Foram realizadas uma aula expositiva dialogada e uma prática em laboratório. Ambas, ocorreram no CEUNES, localizado na Região Norte do Espírito Santo, município de São Mateus. Convém mencionar que essas aulas estavam inseridas em um projeto de extensão denominado "Botânica na Primavera", que teve como intuito desmistificar a ideia de dificuldade no acesso à Universidade pública e gratuita por estudantes da escola pública e promover a popularização da ciência, a partir de experiências vivenciadas em laboratórios de pesquisa lotados nessa instituição, com o enfoque na Ciência Botânica e áreas correlatas.

Foram realizadas três reuniões com a professora responsável do Laboratório de Botânica Estrutural e com oito estudantes dos Cursos de Licenciatura e Bacharelado em Ciências Biológicas e Agronomia (Figura 1) para o planejamento das aulas, na qual foi dividido, para cada monitor (estudante de graduação), um assunto específico, referente à temática proposta do projeto, para ser ministrado de forma expositiva.

Figura 1: Professora e estudantes de graduação participantes das aulas. 


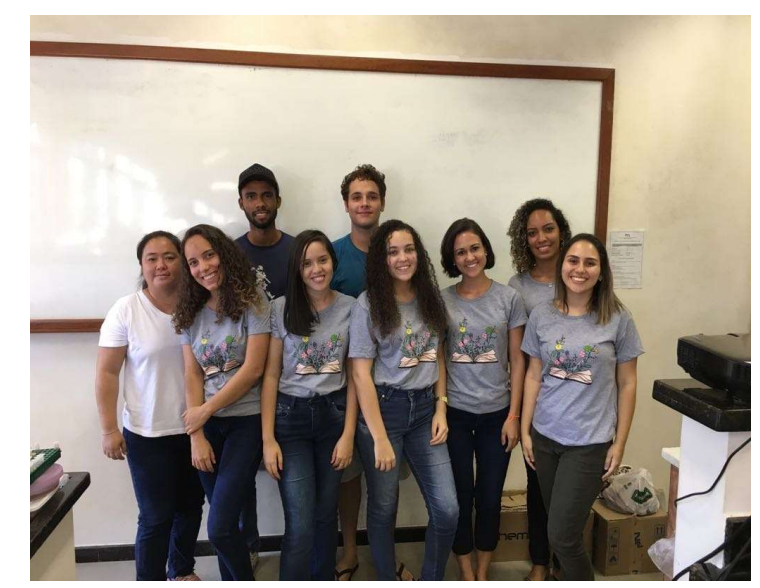

Nesse período de planejamento e trocas de ideias, foi selecionado o título para as aulas, sendo "Adaptação das plantas ao ambiente: há mais do que os olhos podem ver?". Esse tema foi escolhido devido à necessidade de evidenciar a importância da Botânica no cotidiano dos alunos, inclusive no seu desenvolvimento socioeducativo. Além disso, também foi elaborado uma cartilha na qual cada monitor se responsabilizou em elaborar textos temáticos, atividades, curiosidades e imagens no Microsoft Word ${ }^{\circledR}$ (Figura 2). 
cartilha.

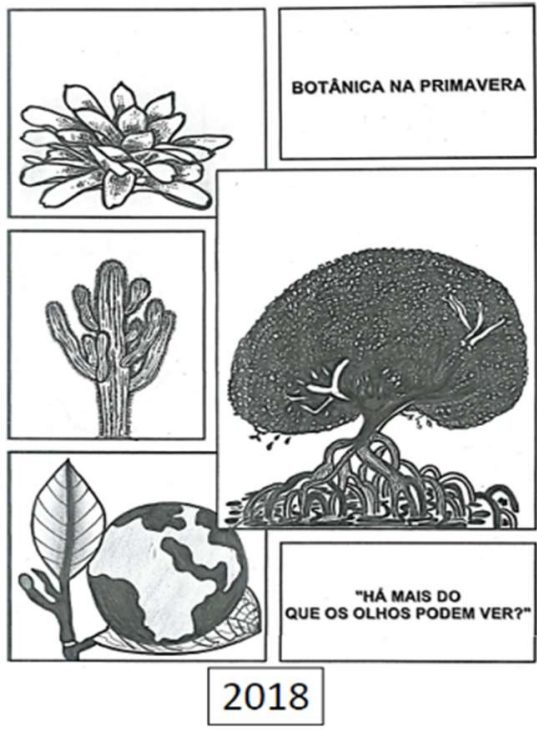

\section{A.DAPTACÕES DAS PLANTAS AO A.MBIENTE}
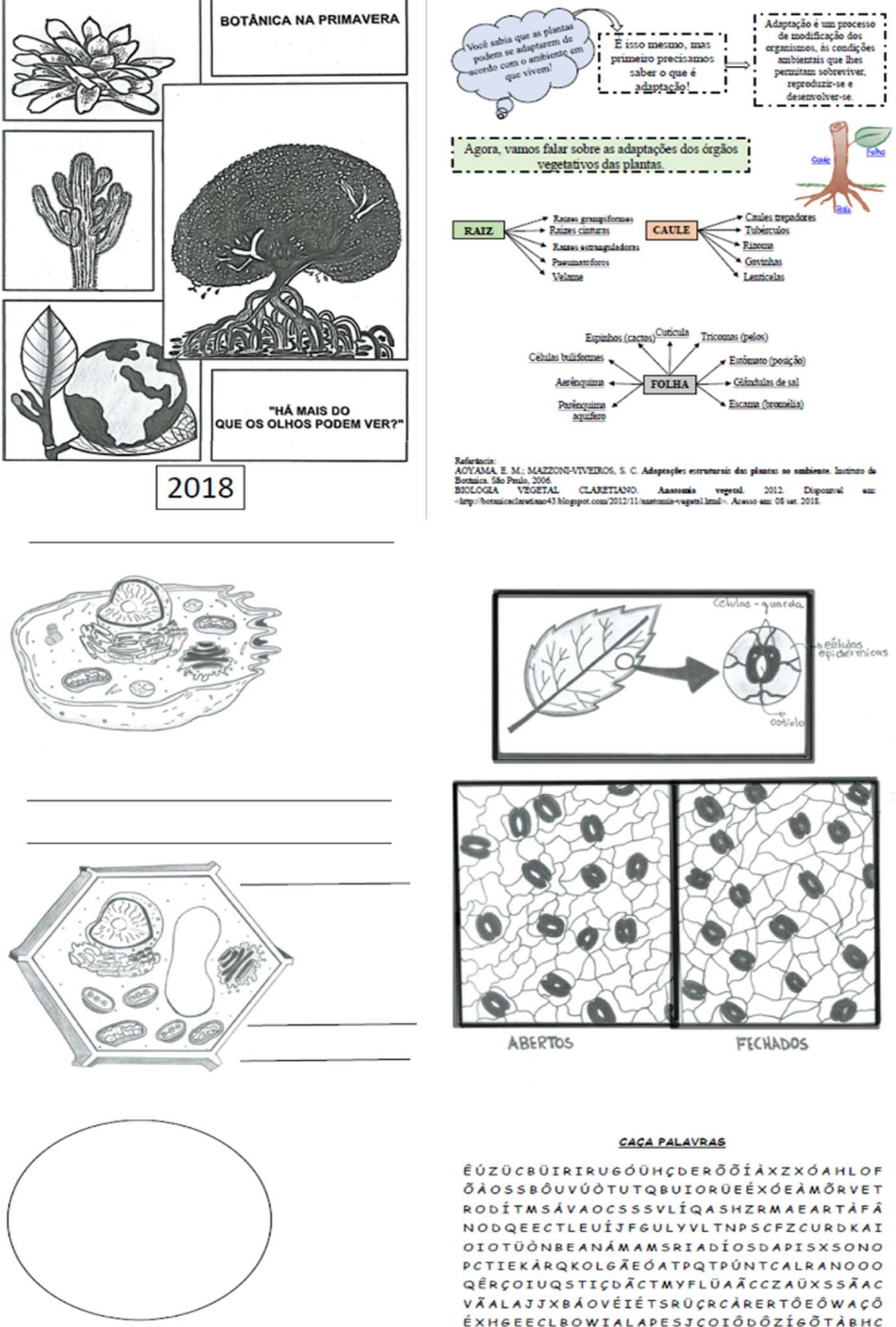

CACA PALAVRAS

ÊÚZÜCBÜIRIRUGÓOUHCDERÕ̃İं̇̉XZXÓAHLOF Ȯ̉OSSBÔUVÚOTUTQBUIORUEEÉXÓEÀMÕRVET RODITMSA VAOCSSSVLIOASHZRMAEARTAंFA NODQEECTLEUÍTFGULYVLTNPSCFZCUROKAI OIOTÜONBEANÁMAMSRIADIOSDAPISXSONO PCTIEKARQKOLGÁEOATPQTPUNTCALRANOOO PCTIEKARQKOLGÃEOATDQTDUNTCALRANOOO QERCOTUQSTICDACTMYFLUAACCZAOXSSAAC VÃALAJTXBAOVETETSROCRCARERTOEOWACOO EXHGEECLBOWIALADESJÇOIODOZIGOTABHC WUMOIBAÓOPOPÁOALATEPOLLYQWTVTPÁCOE
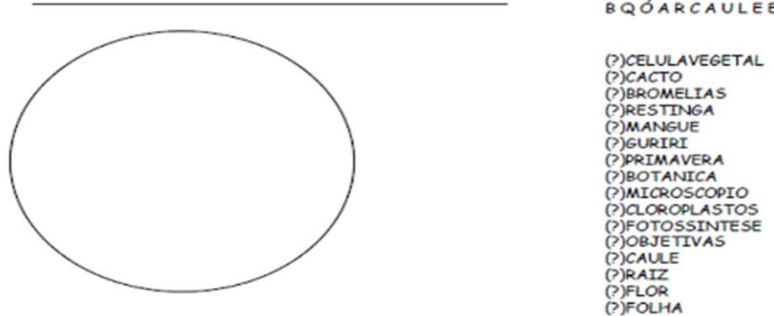
De início, ocorreu uma aula expositiva dialogada, seguida de uma aula prática, ambas no Laboratório de Botânica Estrutural, com duração de 90 minutos. O público alvo foram 25 alunos da $2^{\mathrm{a}}$ série do Ensino Médio de uma escola Estadual, localizada em uma área de vulnerabilidade social.

Esses alunos estudavam no turno matutino e foram à Universidade no turno vespertino para visitarem o espaço da instituição e os laboratórios presentes, bem como interagirem com pesquisadores, professores e universitários. Devido ao espaço do laboratório de Botânica Estrutural e para uma melhor acomodação e desenvolvimento das atividades, os alunos foram divididos em duas turmas. Enquanto uma turma visitava e explorava o laboratório de Ecossistema de Manguezal, a outra participava das atividades sobre morfoanatomia e as relações ecológicas. Após o término, ocorreu a inversão das turmas.

Para a aula teórica, foi utilizado como recurso o Datashow e o Power point ${ }^{\circledR}$. Os conteúdos ministrados pelos monitores foram: célula vegetal; técnicas de utilização do microscópio óptico; técnicas usuais de anatomia vegetal, como planos de corte e montagem de lâminas temporárias e adaptações das plantas ao ambiente. Em relação à aula prática, cada bancada continha materiais vegetais in natura e secções anatômicas transversais e paradérmicas de algumas espécies representativas de cada habitat, que evidenciavam as adaptações das plantas nesse ambiente.

Cada aluno recebeu a cartilha para acompanhar a aula e para realizar anotações, além de ilustrações das estruturas anatômicas e algumas características morfológicas. Com o auxílio do microscópio óptico e estereomicroscópio, puderam observar o material vegetal disponível nas bancadas. Para finalizar, foi aplicado um jogo online (quiz), denominado Kahoot.

\section{Resultados e discussão}

O processo de planejamento das aulas foi de suma importância para os monitores, pois puderam elaborar as suas próprias aulas, estimulando sua criatividade e desenvolvendo habilidades, contribuindo de forma eficaz para a 
sua formação. Segundo Matoso (2014), ser monitor não é somente a obtenção de um título, mas também ganho no aspecto pessoal, por meio do contato direto com alunos, propiciando situações extraordinárias, como contribuir pedagogicamente com o aprendizado de alguns alunos.

Ao longo do desenvolvimento da aula expositiva dialogada, os alunos puderam compartilhar conhecimentos prévios e científicos referentes aos assuntos abordados no momento (Figura 3A-B). Freire (1996) enfatiza que a construção do conhecimento do aluno se dá a partir das suas relações construídas, por meio do diálogo coletivo e assegura-se que:

A dialogicidade não nega a validade de momentos explicativos, narrativos em que o professor expõe ou fala do objeto. $O$ fundamental é que professor e alunos saibam que a postura deles, do professor e dos alunos, é dialógica, aberta, curiosa, indagadora e não apassivada, enquanto fala ou enquanto ouve (FREIRE, 1996, p.33).

Figura 3: A- Professora responsável apresentando o laboratório. B- Monitora ministrando uma parte da aula expositiva.
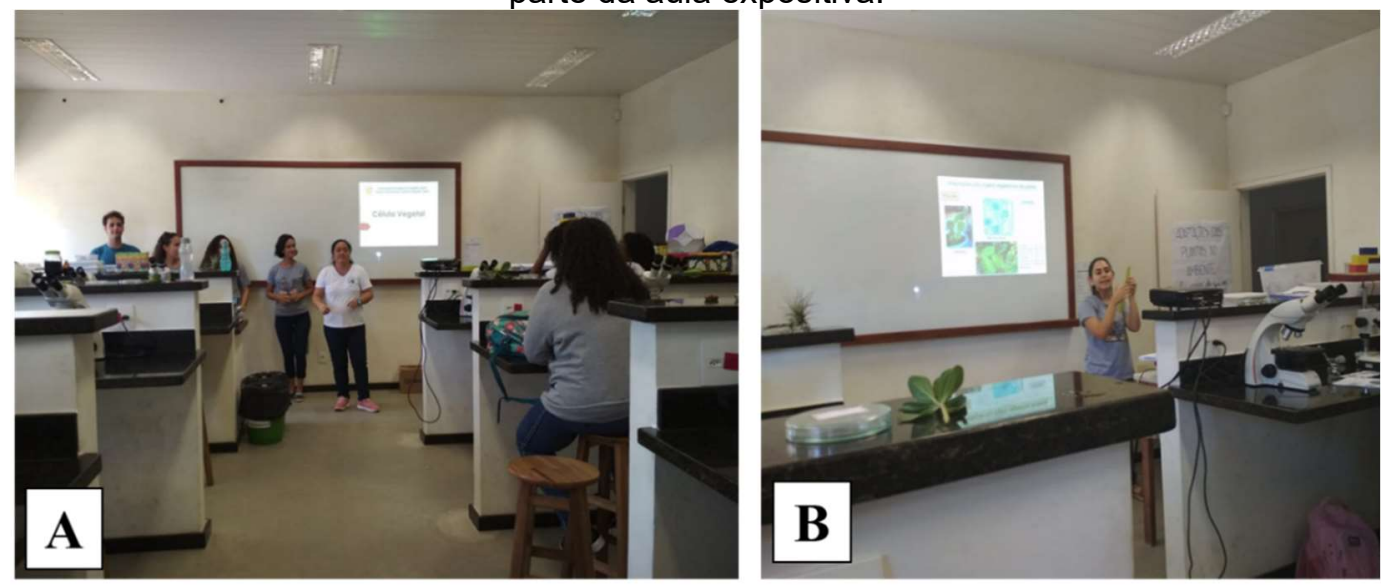

Após essas explanações, os alunos foram divididos nas bancadas presentes no laboratório. Cada bancada continha materiais vegetais (Figura 4 A-B). Para Krasilchick (2016), aulas práticas em laboratórios desempenham algumas funções, como permitir o contato direto dos alunos com fenômenos, manipulando materiais, equipamentos e observando organismos, além de estimular o ensino investigativo, por meio de elaboração de hipóteses, planejamento de experimentos, organização e interpretação de dados. Assim, interfere no entusiasmo, interesse e envolvimento do aluno, bem como no desenvolvimento de sua aprendizagem. 
Figura 4: A- alunos acompanhando a prática com auxílio da cartilha. B - monitora auxiliando o aluno na prática.
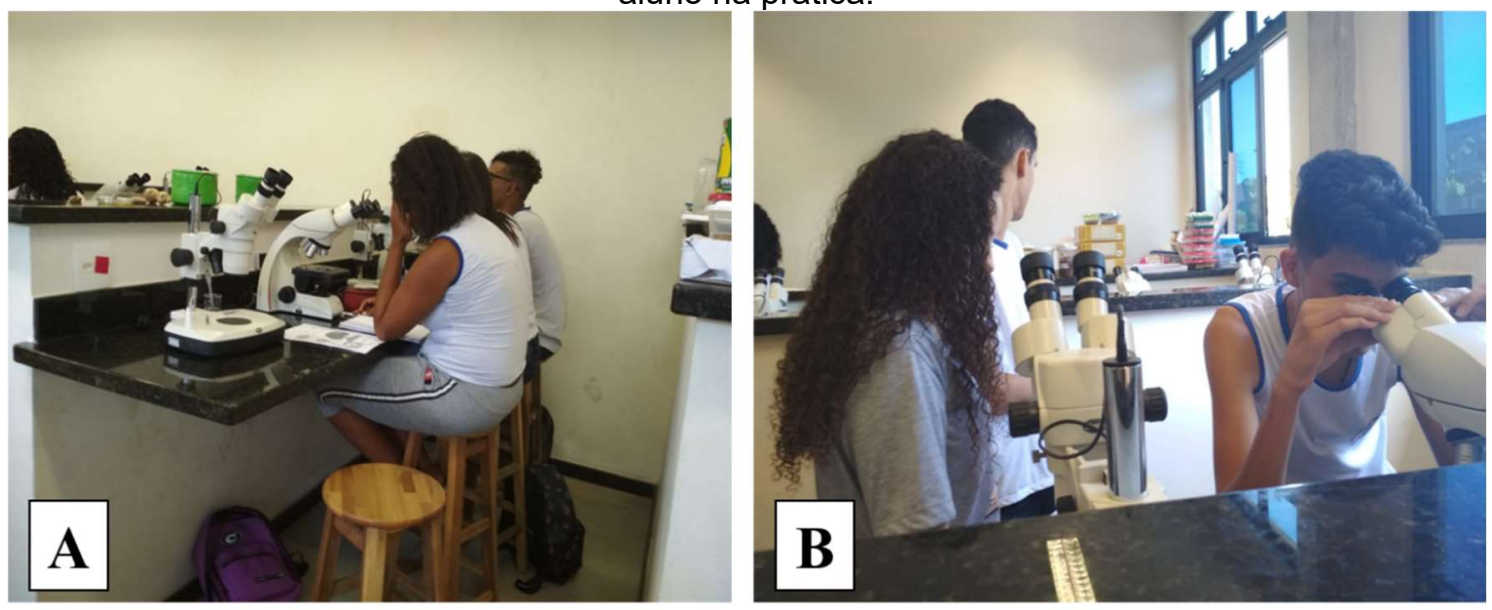

$\mathrm{Na}$ primeira bancada, havia secções transversais e paradérmicas de bromélia Tillandsia sp. (Bromeliaceae) para visualização dos feixes vasculares e das escamas, bem como a planta in natura para mostrar aos alunos que a mesma não possui raiz, realizando a absorção de água e sais minerais por meio das escamas epidérmicas presentes nas folhas.

Na segunda bancada, havia folhas de boldo (Plectranthus ornatus Codd. - Lamiaceae) para visualização dos tricomas na lupa e no microscópio, sendo uma adaptação a ambientes com alta luminosidade, pois os tricomas ajudam na reflectância da luz, além de ajudar na perda de água por transpiração e herbivoria.

A terceira bancada era composta por planta suculenta, evidenciando o armazenamento de água em seus tecidos. A quarta bancada continha folhas de bromélia terrestre, com intuito de comparar com a bromélia epífita da primeira bancada em relação às funções e organização das células das escamas, característica presente na família Bromeliaceae.

$\mathrm{Na}$ quinta bancada, os alunos observaram folhas de Clusia sp. (Clusiaceae) para visualização da cutícula e conhecer sobre as adaptações das plantas ao ambiente em que habitam. Na última bancada, estava exposta uma amostra de açafrão da terra (Curcuma longa L. - Zingiberaceae) e gengibre (Zingiber officinale Roscoe - Zingiberaceae), como exemplos de caules ricos em reservas nutritivas e presentes no cotidiano dos alunos. 
Foi realizado um rodízio para que os alunos observassem todos os materiais disponíveis nas seis bancadas e pudessem realizar perguntas e tirassem dúvidas com os monitores. Após as observações, os alunos formaram grupos para realizarem uma atividade interativa, por meio de um jogo online, denominado Kahoot, em que foi elaborado um quiz (perguntas e respostas) sobre os assuntos abordados durante as aulas (Figura 5A-B). Essa atividade pôde propiciar uma interação entre os alunos e os monitores, bem como alunoaluno, além de ter sido possivelmente uma ferramenta colaborativa com o processo de ensino e aprendizagem.

Figura 5: A e B- Alunos interagindo com os monitores, por meio de um jogo online.

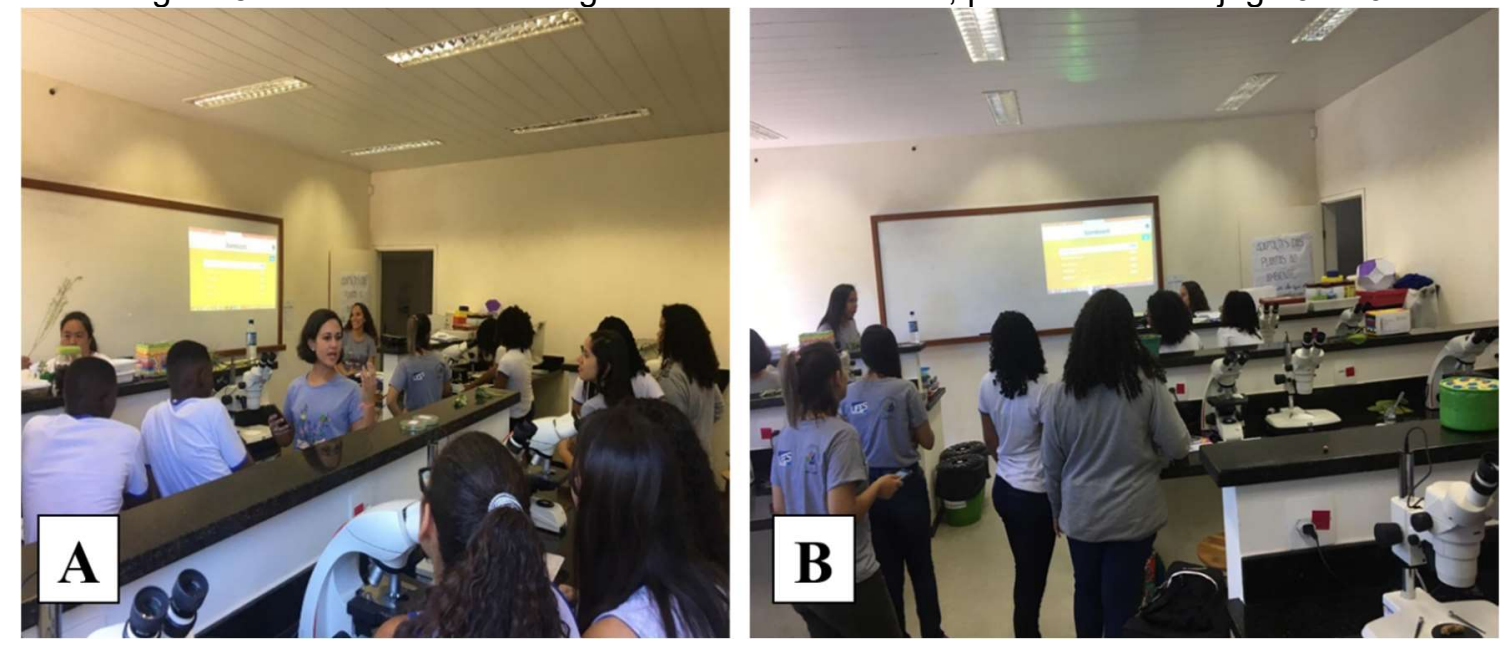

De acordo com Katon et al. (2013), jogos didáticos podem auxiliar os alunos na construção do conhecimento, pois alia aspectos lúdicos aos cognitivos enquanto joga, além de desenvolver iniciativa, imaginação, raciocínio, memória, coletividade, cooperação, socialização, atenção, curiosidade e interesse. Além de que, utilizar estratégias diversificadas ao abordar os conteúdos de ciências, permitem aos alunos trabalharem coletivamente, contribuindo para uma melhor interação e diálogo (BOMBONATO, 2011).

Haja vista que a utilização de jogos digitais pode ser considerada uma estratégia de ensino que interfere positivamente no aprendizado dos alunos, pois, conforme Oliveira (2018), adotar atividades que estejam relacionadas com a vivência (cotidiano) do aluno pode atraí-lo mais facilmente, estimulando os estudos fora da escola de uma forma mais natural, auxiliando na construção do conhecimento e explorando os recursos que o meio proporciona. 


\section{Considerações Finais}

A partir dos resultados obtidos, pôde ser observado que o método pedagógico foi eficaz e que contribuiu com o aprendizado sobre os assuntos botânicos abordados. Além de que, os estudantes de graduação, como futuros pesquisadores e outros também educadores, puderam vivenciar a elaboração e ministrarem suas próprias aulas e conduzirem a prática em laboratório. Assim, essa experiência foi importante na formação profissional, contribuindo para o desenvolvimento da autonomia, interação e desenvolvimento de habilidades dos estudantes de graduação para com os de Ensino Médio.

Vale salientar a importância da visitação dos alunos do Ensino Médio de uma área com vulnerabilidade social à Universidade, pois esses estão restritos às atividades de sala de aula. Embora represente uma ação pontual, essa visita proporcionou aos alunos uma experiência diferente, em um ambiente educacional com uma infraestrutura que permite formas mais dinâmicas e interativas de aprendizagem, complementando o ensino básico, especialmente o ensino de botânica. Ademais, ressalta-se a necessidade das escolas visitarem espaços não formais de ensino com viés educativo, como meio de interação dos alunos com esses ambientes e contribuindo com a construção reflexiva e crítica do aluno.

Para atividades futuras dessa mesma natureza, recomenda-se uma maior duração das aulas práticas ou teóricas, até mesmo uma maior quantidade no número de alunos para visitarem e participarem das atividades disponíveis na Universidade, agregando mais valor à construção de conhecimentos e gerando futuros trabalhos.

\section{Referências}

ANAstasiou, L. G. C.; ALVES, L. P. Estratégias de Ensinagem. 2004. Disponível em: http://www.ufmt.br/proeg/arquivos/2dc95cd453e52a78a17dcc157f04dbf6.pdf>. Acesso em: 26 fev. 2019.

BEZERRA, A. S.; JUNIOR LACERDA, J. C.; TERÁN, A. F. A praça como espaço não formal para a alfabetização ecológica. In: Anais do $3^{\circ}$ Simpósio de Educação em Ciências na Amazônia. Manaus, 2013. 
BOMBONATO, L. G. G. A importância do uso do laboratório nas aulas de Ciências. 2011. 49f. Monografia (Especialização em Ensino de Ciências) Curso de Pós-graduação em Ensino de Ciências, Universidade Tecnológica Federal do Paraná, 2011.

BORTOLETTO, L. Museus e centro de ciências como espaços educativos não formais. In: Atas do IX Encontro Nacional de Pesquisa em Educação em Ciências - IX ENPEC. São Paulo, 2013.

FREIRE, P. Pedagogia da autonomia: saberes necessários à prática educativa. $25^{\circ}$ ed. São Paulo: Paz e Terra, 1996. 54p.

HOFSTEIN, A.; LUNETTA, V. N. The Laboratory in Science Education: Foundations for the Twenty-First Century. Wiley Periodicals, Inc. 2003, p. 127.

KATON, G. F.; TOWATA, N.; SAITO, L. C. A cegueira botânica e o uso de estratégias para o ensino de botânica. In: LOPEZ Alejandra Matiz et al. (Org.). III Botânica no Inverno. Instituto de Biociências da Universidade de São Paulo, São Paulo, 2013. cap. 3, p. 179-182.

KRASILCHIK, M. Prática de Ensino de Biologia. $4^{a}$ ed., $5^{a}$ reimpressão. São Paulo: Editora da Universidade de São Paulo, 2016. 199p.

MATOSO, L. M. L. A importância da monitoria na formação acadêmica do monitor: um relato de experiência. Revista Científica da Escola da Saúde, n. 2, 2014.

MELO, E. A.; ABREU, F. F.; ANDRADE, A. B.; ARAÚJO, M. I. A aprendizagem de botânica no ensino fundamental: dificuldades e desafios. Revista Scientia Plena, v. 8, n. 10, 2012.

OLIVEIRA, L. K. Utilizando as ferramentas digitais na Educação. In: Governo do Estado do Espírito Santo, Secretaria da Ciência, Tecnologia, Inovação e Educação Profissional. 2018.

SALATINO, A.; BUCKERIDGE, M. Mas de que te serve saber Botânica?. Estudos Avançados, v. 30, n. 87, 2016.

\section{Sobre os Autores}

\section{Fabiane Fonseca Ribeiro}

fabifonseca92@gmail.com

Bacharela e Licenciada em Ciências Biológicas pela Universidade Federal do Espírito Santo - campus São Mateus. Pós-graduada em Educação Profissional e Tecnológica pelo Instituto Federal do Espírito Santo. Pesquisadora no Laboratório de Botânica Estrutural e docente na rede privada de Educação Básica. 


\section{Elisa Mitsuko Aoyama}

elisaoyama@yahoo.com.br

Doutora em Biodiversidade Vegetal e Meio Ambiente pelo Instituto de Botânica. Docente no Departamento de Ciências Agrárias e Biológicas (DCAB) da Universidade Federal do Espírito Santo - Campus São Mateus e coordenadora do Laboratório de Botânica Estrutural.

\section{Marcos da Cunha Texeira}

marcosteixeiraufes@gmail.com

Doutor em Entomologia pela Universidade Federal de Viçosa. Docente no Departamento de Ciências Agrárias e Biológicas (DCAB) da Universidade Federal do Espírito Santo - Campus São Mateus e coordenador do Laboratório de Educação Ambiental/Núcleo de Pesquisas e Práticas Pedagógicas em Biologia.

\section{Luis Fernando Tavares de Menezes}

ltmenezes@gmail.com

Doutor em Ecologia pela Universidade Federal do Rio de Janeiro. Docente no Departamento de Ciências Agrárias e Biológicas (DCAB) da Universidade Federal do Espírito Santo - Campus São Mateus, coordenador do Laboratório de Ecologia de Restinga e Mata Atlântica e curador do Herbário SAMES da Universidade Federal do Espírito Santo. 